\title{
16. PRELIMINARY MAGNETIC FABRIC STUDIES OF LOWER CRETACEOUS SEDIMENTS FROM DSDP SITE 397, NORTHWEST AFRICAN CONTINENTAL MARGIN
}

\author{
Norman Hamilton, Department of Geology, University of Southampton, United Kingdom
}

\section{INTRODUCTION}

Measurements of the anisotropy of magnetic susceptibility (magnetic fabric) of sediments provides a rapid means of obtaining grain fabric data. Such data can be interpreted in favorable situations to deduce paleocurrent directions (Hamilton and Rees, 1970) and, where post-depositional deformation has taken place, to infer likely prevailing stress orientations (Graham, 1966; Hamilton and Rees, 1971). The application of magnetic fabric determinations to sediments recovered during the Deep Sea Drilling Project was pioneered by Rees (1971) and Rees and Frederick (1974) who reported studies on Legs 1 through 4.

It was anticipated that a detailed magnetic fabric study on the upper continental rise sediments cored at Site 397 off Cape Bojador might reveal useful information on aspects of the paleoenvironmental evolution of the continental margin. A preliminary attempt to obtain some such data is reported for the Lower Cretaceous strata encountered at this site.

\section{MEASUREMENTS}

The 11 samples selected for magnetic fabric measurement are fully representative of the 155 meters of alternating mudstones with thin dolomicrites which make up the bulk of the Lower Cretaceous sequence. Measurements of the anisotropy of magnetic susceptibility were made using a low-field torque magnetometer (King and Rees, 1962) employing an alternating field of 80 Oe rms.

\section{DISCUSSION OF RESULTS}

The results (Table 1) are given in terms of the spatial orientation of the following three principal axes:

TABLE 1

Magnetic Fabric of Lower Cretaceous Sediments at Hole 397A

\begin{tabular}{|c|c|c|c|c|c|c|c|c|c|}
\hline \multirow{2}{*}{$\begin{array}{c}\text { Sample } \\
\text { (Interval in } \mathrm{cm} \text { ) }\end{array}$} & \multicolumn{2}{|c|}{$\mathrm{K}_{\max }$} & \multicolumn{2}{|c|}{$K_{\text {int }}$} & \multicolumn{2}{|c|}{$\mathrm{K}_{\min }$} & \multirow[b]{2}{*}{ h $(\%)$} & \multirow[b]{2}{*}{$q$} & \multirow[b]{2}{*}{$f\left({ }^{\circ}\right)$} \\
\hline & Dec & Inc & Dec & $\ln c$ & Dec & Inc & & & \\
\hline $35-2,75-77$ & 106 & 3 & 16 & 2 & 256 & 85 & 3.80 & 0.076 & 5 \\
\hline $37-2,136-139$ & 50 & 8. & 319 & 8 & 187 & 77 & 5.18 & 0.104 & 13 \\
\hline $39-2,34-36$ & 6 & 12 & 274 & 10 & 146 & 73 & 2.01 & 0.259 & 17 \\
\hline $40-2,124-125$ & 244 & 3 & 154 & 0 & 59 & 86 & 3.13 & 0.126 & 4 \\
\hline $42-1,60-62$ & 339 & 6 & 249 & 2 & 138 & 82 & 4.36 & 0.042 & 8 \\
\hline $46-1,126-128$ & 65 & 0 & 335 & 4 & 142 & 85 & 4.51 & 0.102 & 5 \\
\hline $47-1,108-110$ & 55 & 3 & 145 & 0 & 249 & 86 & 5.18 & 0.086 & 4 \\
\hline $48-2,38-40$ & 82 & 3 & 352 & 10 & 188 & 78 & 4.07 & 0.073 & 12 \\
\hline $50-4,80-84$ & 340 & 10 & 249 & 8 & 118 & 76 & 1.31 & 0.313 & 14 \\
\hline $51-6,85-86$ & 250 & 6 & 159 & 8 & 19 & 79 & 3.70 & 0.193 & 11 \\
\hline $52-3,73-75$ & 329 & 3 & 60 & 26 & 232 & 63 & 3.23 & 0.072 & 27 \\
\hline
\end{tabular}

Note: All declinations are referred to an arbitrary azimuth for each sample. the maximum susceptibility axis $\left(\mathrm{K}_{\max }\right)$, the intermediate susceptibility axis $\left(\mathrm{K}_{\mathrm{int}}\right)$, and the minimum susceptibility axis $\left(\mathrm{K}_{\min }\right)$.

Combination of the magnitudes of the principal axes of susceptibility leads to a variety of fabric parameters. We choose percentage anisotropy, $h$ :

$$
h=100 \frac{\left(\mathrm{K}_{\max }-\mathrm{K}_{\min }\right)}{\left(\mathrm{K}_{\text {int }}\right)}
$$

and $q$, the azimuthal anisotropy quotient (Rees, 1965):

$$
q=\frac{\mathrm{K}_{\max }-\mathrm{K}_{\mathrm{int}}}{\left(\mathrm{k}_{\max }+\mathrm{K}_{\mathrm{int}}\right) / 2-\mathrm{K}_{\min }}
$$

to follow the convention adopted in earlier studies on the magnetic fabric of sediments. A parameter $f$ (Crimes and Oldershaw, 1967) measures the angular deviation of the $\mathrm{K}_{\min }$ axis from the pole to the bedding plane. Hamilton and Rees (1971) show that the magnitudes of $q$ and $f$ can be used to discriminate between varied fabric types.

Percentage anisotropies at Site 397 are in the range 1.3 through 5.2 per cent and $q$ values are mostly low. This reflects the dominance of the magnetic foliation over the magnetic lineation. With the exception of Sample 397 A-52-3, $73-75 \mathrm{~cm}$, all the samples are characterized as possessing a primary style magnetic (depositional) fabric (Hamilton and Rees, 1970.) A primary style fabric is typified as one whose $q$ value is in the range $0.04<q<0.67$ and which has an $f$ value of less than $15^{\circ}$. It reflects essentially undisturbed sediment accumulation; values outside these ranges are often indicative of deformational processes.

The samples from Cores 35 and 40 through 47 give the smallest $f$ angles and have $q$ values of less than 0.13 . These intervals in the sediment sequence contain the highest proportion of very thin varve-like laminae (rhythmites, Einsele and von Rad, this volume). In contrast, a marginally higher value of $q$ is recorded for Sample 397A-39-2, 34-36 cm ( $q=0.259)$ together with an increase in $f$ angle to $17^{\circ}$. This may reflect the intercalcation at this level of thin distinct clastic layers (sand/silt) often showing small-scale cross-bedding. Such intercalations suggest an episode of grain transport by increased bottom current flow.

Samples from Cores 50 and 51 also show a localized increase in $q$ value. As the lithologic log records increasing deformation here variable $q$ could be anticipated together with higher $f$ values. The sample from 
Section 52-3 may be considered as somewhat anomalous in view of its much greater than average $f$ angle of $27^{\circ}$, again reflecting increasing deformation. We have not encountered in this Cretaceous sequence any true secondary style fabrics similar to those which have been recognized in earlier studies of sediments affected by marked tectonic deformation (Graham, 1966; Hamilton and Rees, 1971).

We can use the remanence directions of the individual samples in an attempt to recover an absolute azimuthal orientation for their principal axes of magnetic susceptibility. The declination of the remanence direction, normally that given after 300 Oe demagnetization, is taken to indicate the direction of the geographic meridian at the time of deposition or acquisition of magnetization. An azimuthal error of a few tens of degrees may be present in such estimates of the meridian if secular variation has not been fully averaged out, a possibility if high sedimentation rates prevailed. Nevertheless, adopting this procedure and replotting the fabric axes with respect to their associated remanence declination provides a means for comparison of the orientations of the maximum susceptibility axes throughout the Lower Cretaceous sequence. Figure 1 shows the maximum and minimum susceptibility axes referred to this common meridian direction.

Two different groupings of maximum susceptibility axes emerge, a near north/south trend (Cores 35 and 40 through 47) and an east-south-east/west-north-west trend (Cores 39, 48, 50, and 51). Too few fabric results

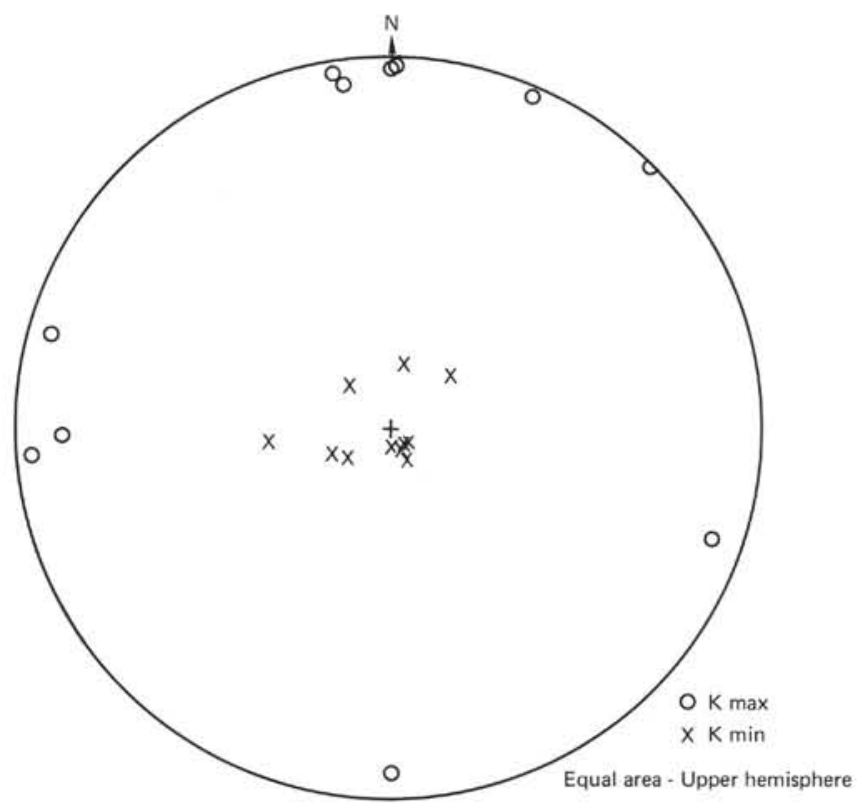

Figure 1. Distribution of maximum and minimum principal susceptibility axes of Lower Cretaceous sediments at Site 397. are available to fully assess the significance of these trends. If, as maintained in earlier studies (Hamilton and Rees, 1970), the maximum susceptibility axis is an indicator of paleocurrent direction, then we can speculate that the north/south trend reflects a sediment transport path parallel to a protocontinental margin while transverse transport occasioned possibly by downslope movement gives rise to the other preferred orientation trend. Such a duel direction of sediment transport is compatible with the interpretation of Einsele and von Rad (this volume) that these Lower Cretaceous sediments accumulated in a distal prodelta slope environment. A more proximal location should give rise to magnetic fabrics with a preponderance of secondary style fabrics and possibly showing a predominance of maximum susceptibility axes grouped in a downslope direction. However, we cannot dismiss immediately an alternative explanation that for these predominantly fine-grained siltites, magnetic field control produces the north/south grouping of maximum susceptibility axes and only the east/west group reflects a true sediment transport direction. Resolution of these alternatives requires more detailed fabric study on other samples from this Cretaceous sequence.

\section{ACKNOWLEDGMENTS}

I am grateful to A. I. Rees for reviewing this manuscript and to A. A. Manighetti for assistance with the measurements.

\section{REFERENCES}

Crimes, T. P. and Oldershaw, M. A. 1967. Paleocurrent determinations by magnetic fabric measurements on the Cambrian rocks of St. Tudwal's Penisula, North Wales, Geo. Jr., v. 5, p. 217-232.

Graham, J. W . 1966. Significance of magnetic anisotropy in Appalachian sedimentary rocks. In Steinhart, J. S. and Smith, T. J. (Eds.), The earth beneath the continents: Am. Geophys. Union Mono., no. 10, p. 627-648.

Hamilton, N. and Rees, A. I. 1970. The use of magnetic fabric in palaeocurrent estimation. In Runcorn, S. K. (Ed.), Palaeogeophysics: London (Academic Press), p. 445-464. 1971. The anisotropy of magnetic susceptibility of the Franciscan Rocks of the Diablo Range, Central California, Geol. Rundshau, v. 60, p. 1103-1124.

King, R. F. and Rees, A. I., 1962. The measurement of the anisotropy of magnetic susceptibility of rocks by the torque method, J. Geophys. Res., v. 67, p. 1565-1572.

Rees, A. I., 1965. The use of anisotropy of magnetic susceptibility in the estimation of sedimentary fabric, Sedimentology, v. 4 , p. $257-271$.

1971. The magnetic anisotropy of samples from the Deep Sea Drilling Project Leg 1, Orange, Texas To Hoboken, N. J., Marine Geol., v. 11, p. M16-M23.

Rees, A. I. and Frederick, D., 1974. The magnetic fabric of samples from the Deep Sea Drilling Project, Legs 1-V1, J. Sediment. Petrol., v. 44, p. 655-662. 